\title{
De la economía política a la economía pública: José Canga Argüelles
}

\author{
Marcello CARMAGNANI \\ El Colegio de México-Fondazione Luigi Einaudi \\ mkarmag@tin.it
}

Received: 06/02/2016

Accepted: 04/09/2016

\begin{abstract}
Resumen
El objetivo de este estudio es ilustrar cómo la economía clásica contribuyó al nacimiento de una nueva doctrina liberal relativa a las finanzas públicas gracias a los escritos teóricos y al empeño como funcionario público de José Canga Argüelles entre los últimos decenios del siglo XVIII y el primer tercio del siglo XIX.

Los vínculos entre la economía, la moral y la política permitieron a Canga Argüelles articular la economía política con la hacienda pública. Fue la era en que nació una nueva definición de las finanzas públicas que toma en cuenta la relación que se establece entre la riqueza y el gasto público facilitando la reorganización de la imposición fiscal. Esta nueva relación entre los gastos e los ingresos redefinió también a su vez el crédito público a través el reconocimiento de todas las deudas de la nación que permite establecer una nueva relación de confianza entre el Estado, los acreedores y los ciudadanos.
\end{abstract}

Palabras clave: economía política, hacienda pública, España, Canga Argüelles

Clasificación JEL: B12, E62, G18, H60, N23

From political economy to public economics: José Canga Argüelles

\begin{abstract}
The purpose of this essay is to illustrate how classical economics contributed to the breakthrough of new liberal thought of public finances in Spain mainly due to the theoretical contribution and public action of José Canga Argüelles at the turn of $18^{\text {th }}$ Century and the first decades of the $19^{\text {th }}$ Century.

The relation between economics, morality and politics allowed Canga Argüelles to articulate economics and public finances. He conceived a new definition of public finances which establishes a close relationship between wealth and government spending which eases the reorganization of taxation. This new relationship between expenditures and revenues also redefined the public credit through the recognition of all public debts that allowing for a renewal of trust between state, creditors and citizens.
\end{abstract}

Keywords: Political economy, public finances, Spain, Canga Argüelles

JEL Classification: B12, E62, G18, H60, N23

\section{Introducción}

En el siglo XVIII asistimos a la progresiva autonomía de la economía política de las disciplinas moral y política. La economía asume un papel importante en el desarrollo de la opinión pública pues hablar y escribir de economía es una nueva forma de hacer política evitando la censura. El principal objetivo de este artículo es ilustrar cómo a partir de la economía política se desarrolla la nueva ciencia de las finanzas públicas que José Canga Argüelles denominó economía pública.

Gracias al excelente estudio de Palmira Fonseca Cuevas (1995) y a la contextualización ofrecida por Perdices de Blas y Reeder (2003), disponemos de una adecuada información del papel que jugó José Canga Argüelles en el nacimiento de la ciencia de las finanzas públicas. Con base a estos precedentes elaboré un itinerario analítico que toma en cuenta, como acontece para la mayoría de los economistas clásicos, los vínculos de sus ideas con la moral y la política para ilustrar cómo a partir de su formulación de la economía política reelabora la concepción de la riqueza con el fin de ofrecernos su idea de la riqueza pública.

Gracias a su concepción de la riqueza pública, Canga comprende que el gasto público es el motor de la hacienda pública capaz de definir la imposición fiscal y la deuda pública y que la 
riqueza pública es la que favorece una nueva relación entre el gobierno, los acreedores de la hacienda y los ciudadanos que contribuyen al sostén del Estado.

\section{Moral y política}

Para comprender la doctrina económica de José Canga es necesario tomar en cuenta el papel que tuvo la enseñanza de Lorenzo Normante y Carcavilla en su formación. Normante fue el primer titular de la cátedra de economía política fundada en 1784 por la Real Sociedad de Amigos del País de Zaragoza y es el autor de las Proposiciones de economía civil y comercio que reproduce las lecciones que dictó a sus alumnos.

En estas lecciones Canga Argüelles comprende que la economía política "se dirige a fomentar el aumento y el bienestar del género humano" pues su objetivo es "la felicidad pública" (Normante, 1784, pp. 42 y 118). Normante sostuvo también que la sociedad civil, con la ayuda de las Reales Sociedades de Amigos del País, generaliza "el amor de la patria" cuya solidez depende de "los conocimientos económicos" (Normante, 1784, p. 47). Las ideas de Normante impartidas a sus estudiantes consideran que la educación "necesaria para la prosperidad pública" requiere el conocimiento de la física, la mecánica, la moral y la filosofía del entendimiento (Normante, 1785, pp. 72 y 77-78).

En las clases de Normante, Canga escucha hablar de la libertad económica, comercial y de la circulación de la moneda, así como de la relación existente entre la economía, la hacienda pública y el poder de la nación, argumentos que más tarde se convertirán en centrales en su pensamiento (Normante, 1785, pp. 101-105, 108-111 y 113-118). También en la cátedra de Normante se familiariza con los economistas españoles, desde Uztáriz a Campomanes, los italianos, los franceses y los ingleses. De allí que ya en su fase de formación conecte estrechamente la moral con la política, que es el tronco de donde nace la economía política.

Gracias a información proporcionada por Fonseca Cuevas (1995) se logra seguir la formación inicial como la del periodo siguiente a través del estudio de su círculo cultural. A diferencia de la red cultural, el círculo cultural crea una relación unidireccional que conecta un autor, en este caso Canga, con una multiplicidad de autores a través del estudio y el conocimiento de sus obras aun cuando no da vida a una relación multidireccional con ellos, como en cambio acontece en una red cultural (Simmel, 1908 y Pescosolido y Rubin, 2000).

Gracias al catálogo de los economistas que enumera nuestro autor en su Diccionario de Hacienda, que contiene 347 títulos, y al catálogo de sus lecturas que contiene 1.149 títulos, se logra establecer un buen acercamiento a sus conocimientos (Fonseca Cuevas, 1995, pp. 131-134 y 562-603). El primer catálogo contiene 103 obras económicas (desde los tratados generales hasta la política económica), 83 obras de hacienda pública y 57 obras relativas al "remedio general del Reino" que comprenden obras de moral y política.

De mayor interés para el conocimiento del círculo cultural de Canga es el catálogo de lecturas que contiene 1.149 títulos, 267 atañen a la economía política (23.2\%), 234 a la historia (20.3\%), 183 a la hacienda pública (16 \%), 88 al derecho (7.7\%), 54 a la política (4.7\%) y 37 a la administración pública (3\%). Sabemos que concedió gran importancia a la historia para comprender la hacienda pública pues en 1835 disertó sobre la "necesidad que los hacendistas tienen de dedicarse al estudio de la historia" (Martínez Cochero, 1977, pp. 10-16).Hasta el final de su vida, conservó el interés también por los estudios morales, jurídicos y políticos. Se logra así comprender que incluso en su última obra el Diccionario de Hacienda de 1833-1834, sus conceptos centrales de la virtud, la utilidad, el valor la libertad y la constitución articulan la moral con la economía y la hacienda pública.

Su interés por la dimensión moral deriva de sus lecturas de Locke, Hume, d'Holbach, Montesquieu, Filangieri, Mably, Condillac y Rousseau, así como su pensamiento liberal está asociado a Jovellanos, Cabarrús y sin lugar a dudas Flórez Estrada (Fonseca Cuevas, 1995, pp. 131135 y 532-603). En el prólogo de su Diccionario de Hacienda sostiene, citando a Pietro Verri, "que el valor depende de la utilidad" porque "es la mayor o menor aptitud que el hombre reconoce en los bienes que sirven para satisfacer sus necesidades" (Canga Argüelles, 1833-1834, I, III).

La relación entre moral, política y economía es expuesta en sus Reflexiones sociales publicadas en 1811, donde ilustra "un horizonte ideológico lleno de referencias políticas como aquellas 
que configuraron el riquísimo y plural debate preconstitucional en España" (García Monerris 1996,203-228 y 2000, LXII). En el prólogo de sus Reflexiones insiste en la necesidad de conocer "los derechos y deberes del hombre constituido en sociedad" los cuales son los derechos naturales "que el hombre tiene en sí mismo" y "cuya conservación procura cuando se reúne con sus semejantes, o lo que es igual, cuando constituye las sociedades" (Canga Argüelles, 1811a, p. 7). Es la nación que proclama "la ley suprema" que "se conoce bajo el nombre de Constitución" que subsume la virtud de la razón que al unirse con el sentimiento hace posible convertir los deseos en necesidades útiles a los hombres y a la sociedad (Canga Argüelles, 1811a, pp. 8$10)$.

En el año de 1811, cuando Canga es ministro de hacienda, los principios morales son reconfirmados para hacer frente a la crisis del crédito público. Escribe el nuevo ministro que "la moral de los gobernantes no puede ser distinta a la de los individuos" y no se deben desconocer "los clamores del que reclama sus derechos" de acreedor de la hacienda. Refuerza esta idea argumentando que "la teoría del crédito [público] tiene una íntima conexión con la moral" pues si los ciudadanos no confían en el gobierno "olvidan sus relaciones con la Patria" y se difunde "la indiferencia sobre la suerte del Estado, precursora de su ruina" (Canga Argüielles, 1811b, p.783).

En su Diccionario de Hacienda define la moral en términos propios de la Ilustración como "la ciencia de vivir bien, y de encaminar las acciones humanas a la felicidad y a la perfección" y que ella es "conforme a la ley natural" que se aplica tanto a los hombres como a la sociedad y a las componentes de la misma (Canga Argüelles, 1833-1834f, II, p. 340).

La moral virtuosa sostenida por "los adelantamientos de la industria" favorece "la unión de los ciudadanos". Esta unión es imposible si "llevan los unos el peso de las contribuciones, mientras otros se miran libres" con lo cual se "interrumpe la armonía que deben guardar todas las clases" (ibíd.). Concluye su artículo señalando "el íntimo enlace que con la hacienda tiene la moral" en cuanto "ciencia que señala los deberes que los directores y los empleados tienen", "sin dañar a las costumbres sanas ni al bienestar del contribuyente" (ibíd.).

En sus Elementos de la ciencia de hacienda escribe que la civilización vincula la moral con la política, la seguridad, la salud, las costumbres, el culto y la comodidad de los consumos bajo el argumento que influyen "directamente en la industria" y por lo tanto en el desarrollo de la economía. Sostiene también que todos los elementos de la civilización "prosperan en donde ejercen su poderoso influjo" mientras son ausentes en los países no civilizados. Subraya que las costumbres que se presentan asociadas con la moral pública animan el trabajo pues "las virtudes son bases del bienestar de las naciones" (Canga Argüelles 1825, 17-18).

A la luz de las ideas morales se logra comprender mejor la predilección de Canga por un liberalismo constitucional que asigna un papel importante a los derechos naturales de la libertad, la igualdad y la propiedad. La libertad se asocia con la seguridad que es "la facultad de hacer con seguridad cuanto le pareciere más acomodados a sus deseos, siempre que con ello no daña a los demás hombres". La igualdad se asocia con la propiedad pues es "es el derecho para ser protegido en sus medios, y en sus facultades, sin diferencia de unos hombres con otros". La propiedad asume una gran centralidad pues es "la facultad exclusiva de disponer y gozar a nuestro arbitrio del producto de nuestro trabajo" (Canga Argüelles, 1811a, pp. 7-8).

Los derechos del hombre requieren de "una fuerza capaz de contener al díscolo, de apartar las sugestiones de la ambición, y los efectos funestos de las pasiones" los cuales dan origen al principio de la seguridad "que es el conocimiento que tiene el hombre, de que nada podrá perturbarle en el disfrute de sus derechos" (Canga Argüelles, 1811a, p. 8).

La importancia que Canga atribuye a la propiedad y a la seguridad permite caracterizarlo como un liberal similar a los intelectuales y políticos presentes en la escena política en los primeros decenios del siglo XIX. Su pensamiento influenciado por las ideas morales propias de la última fase de la ilustración ilustra el pasaje hacia el liberalismo.

\section{Economía política}

Recordé en el párrafo precedente el papel desempeñado por Normante en la formación económica de Canga, que lo ayudó a llegar en 1798 a la Secretaría de Estado y Despacho Universal de Hacienda como oficial. No sorprende que en 1801 Canga Argüelles presente a la Sociedad Eco- 
nómica de Amigos del País de Mallorca una memoria que testimonia sus ideas favorables a la libertad de circulación de todos los bienes comprendida la moneda. Se opone a la decisión de la Junta General de Comercio y Moneda de impedir la libre circulación de la moneda en España con el pretexto "que la moneda sirva de precio de las cosas". Argumenta, en cambio, que la circulación de la moneda "está sujeta a las leyes de los demás géneros" y sostiene que la Junta confunde el valor con el precio. El valor desciende de la necesidad de una mercancía mientras el precio es la evaluación que cada individuo atribuye a una mercancía. De allí que impedir la circulación de la moneda "solo aumenta el precio de los géneros "pues el precio es el resultado del encuentro entre la demanda y la oferta (Canga Argüelles, 1801,1833-1834, I, p. 460).

Canga escribe que al bloquearse la libre circulación monetaria se afecta a la oferta de mercancías y, por lo tanto, se la perturba con leyes prohibitivas que perjudica la industria nacional y el consumo pues España es rica en metales preciosos provenientes de sus colonias, las cuales "cambian su plata por los efectos que carece". Reprocha también a los funcionarios que perturban el transporte de dinero hacia las fronteras de tierra y de mar con el resultado que "obstruyen el círculo de una riqueza" al "impedir la salida de dinero" lo cual aniquila la riqueza de España que obtiene por "ser dueña de las minas" de América (Canga Argüelles, 1801, 1833-1834. I, p. 461).

Décadas más tarde reafirma la importancia de la economía monetaria comentando la obra de Destutt de Tracy, Traité d'économie politique (1823). En su artículo llega a la conclusión que el valor de la moneda depende de los metales que la componen que, al igual que todas las mercancías, su valor depende "de la escasez o abundancia de los metales de que se componen" (Canga Argüelles, 1833-1834, I, p. 352).

En 1802, apenas un año después de su primera Memoria, da prueba de su capacidad de conjugar su conocimiento de la historia con la economía y la hacienda pública analizando el desempeño económico español en los últimos decenios del siglo XVIII.

En los "diez años continuados de paz entre 1783 y 1793 aumentan la riqueza y la población”. En esta fase de crecimiento, la agricultura, las artes y el comercio se expandieron y enriquecieron el erario, mientras en los diez años siguientes, entre 1793 y 1802, es de inercia pues España tuvo que dar vida al papel moneda y desapareció "el espíritu de empresa por falta de capitales y de confianza" (Canga Arguielles, 1802, 1833-1834, I, p. 636). A Canga le interesa sobremanera señalar que el responsable de esta fase de inercia fue la guerra de los Siete Años (1756-1763) que costó al erario 7 mil millones de reales y generó una deuda pública de 4,1 millones de reales en España y una deuda similar en América (Canga Argüelles, 1802, 1833-1834, I, p. 638).

La situación de la hacienda le permite indicar "las reformas oportunas para elevar la nación al alto punto de consideración que se merece". Se trata de reformar "los gastos de la corona en tiempo de paz", verificar los "abusos que hay en ellos" e introducir las "reformas que parecen necesarias" que derivan de los gastos de guerra. El temor a la censura lo obligaron a dar a sus críticas un tono muy moderado (Canga Argüelles, 1802, 1833-1834, I, p. 649).

En el periodo que precede y acompaña el Congreso de Cádiz vemos que Canga utiliza los mismos datos de 1802 para escribir que corresponde ahora a "la nación" reunida en Cortes examinar los gastos de la corona con el fin de reducirlos y señalar a cada clase su cuota de impuestos" con el fin de "liquidar la deuda, determinar los medios de su pronta extinción, establecer como se hayan de satisfacer las obligaciones" y asegurar los ingresos y los gastos públicos "por medio de un sistema exacto de cuenta y razón" (Canga Argüelles, 1811a, p. 57). La guerra requiere una regeneración de la economía con el objetivo de equilibrar los gastos con los ingresos y poner bajo control la deuda pública.

A través de sus Elementos de la ciencia de la hacienda y sus artículos del Diccionario de Hacienda se logra precisar su visión de la economía política partiendo de la idea que "la ciencia de hacienda es parte de la economía política" (Canga Argüelles, 1825, p. 12). En el Diccionario de Hacienda escribe que la economía política o civil es la "ciencia que descubre las causas y los medios por los cuales la riqueza pública se aumenta y distribuye en las clases de la sociedad". Se trata, agrega, de una ciencia experimental que por medio de "la observación exacta y repetida de un mismo resultado, procedente siempre de hechos iguales, forma un axioma, y la unión de éstos, la ciencia económica" (Canga Argüelles, 1833-1834c, I, p. 532). 
$\mathrm{Al}$ sostener que el método de la economía política es de tipo inductivo-deductivo reconduce la hacienda pública al mismo método. De allí que Canga pertenezca a la generación de los liberales con un interés teórico y aplicado a la economía pública. Es este doble interés que le consiente sostener que la agricultura, el comercio y las artes "por las relaciones que tienen con el aumento o disminución de la riqueza, indica los casos en que el comercio es verdaderamente productivo o perjudicial; y enseña apreciar cada operación por sus resultados" (ibíd.).

Para Canga la economía política tiene como objetivo generar riqueza. Por riqueza entiende "la posesión de las cosas útiles, capaces de cubrir nuestras necesidades" (Canga Argüelles, 1833-1834i, II, p. 529). El principal agente de la riqueza es el trabajo que "aplicado a los objetos que nos presenta la naturaleza produce un capital". Este último, da vida a "los valores que dan los capitales". El resultado es que "la riqueza de las naciones se reduce a aumentar la suma de valores" que no son solo las producciones, el comercio y el consumo sino también todo el conocimiento y la división del trabajo necesarios para generar utilidad, eliminar la escasez y favorecer el deseo de aplicar a las necesidades. La riqueza se distribuye "rápidamente entres las clases de la sociedad" a condición que no existan obstáculos derivados de la naturaleza o de la política. Es en su distribución que se "forma la riqueza general de la nación" (Canga Argüelles, 18331834b, I, p. 361).

La riqueza es así un concepto dinámico que gracias a la conjunción entre el trabajo y el capital generan los bienes que son los que permiten a los productores y a los capitalistas obtener un flujo de ingresos variables en el tiempo y en el espacio.

Si bien es evidente la influencia de Adam Smith en su análisis de los agentes de la riqueza, al hablar de la división del trabajo la limita especialmente al trabajo industrial. Para Canga, la división del trabajo es "la distribución de la maniobra que se emplea sobre las materias primeras, entre varios individuos" que "lo admiten muy grande las manufacturas, pequeña la agricultura; y el comercio guardan un medio". Da también mucha importancia al sensualismo de Condillac y Destutt de Tracy al sostener que la división del trabajo "facilita la aproximación de los objetos útiles a los deseos" que considera el principal fundamento de la "reproducción de la riqueza" (Canga Argüelles, 1825, pp. 12-14).

Canga define el capital como "un fondo de las cosas útiles, dedicado a la producción de otros objetos materiales, útiles para satisfacer necesidades" que ilustra la influencia de los economistas sensualistas en su pensamiento (Canga Argüelles, 1825, pp. 14-15). Ilustra muy bien la diferencia entre el capital fijo y el circulante, citando el Cours d'économie politique de Henri Storch (1823), para sostener que el trabajo y la riqueza "no sigue la razón directa de la extensión del campo ni del número de talleres y de los operarios, sino la del capital circulante" (Canga Argüelles, 1825, p. 16).

También Storch es un autor importante para Canga por la importancia que asigna al consumo como "las cosas que el hombre adquiere capaces de llenar sus deseos" pero que "no exceden de la suma precisa para la satisfacción momentánea de éstos". Así retoma la distinción, ya reconocida a mediados del siglo XVIII, del consumo de bienes básicos, de los bienes de "cómodo" o secundarios y de los bienes de lujo (Canga Argüelles, 1825, pp. 16-17).

Su análisis del consumo le sirve para ilustrar la existencia de una parte del ingreso que no es consumido y por lo tanto ahorrado "con el fin de dedicarlo a la reproducción de las riquezas" que considera la "causa inmediata de la formación y acumulación de los capitales", agregando que dicha acumulación no debe confundirse con el atesoramiento, que es un "capital estéril" (ibíd.).

Su interés por la riqueza y por la acumulación del capital está en relación con su interés principal, la hacienda pública. Con este fin sostiene, citando Pietro Verri, que la riqueza engrandece el Estado si se emplea "en utilidad suya" (Canga Argüelles, 1825, p. 5).

Canga acoge el tránsito de la opinión pública desde la esfera de la moralidad a la escena política y a las ideas económicas que acontece entre el periodo terminal de la Ilustración y el debate constitucional de Cádiz (Fernández Sebastián, 2015, pp. 213-233). En 1811 escribe que uno de los hechos positivos de la insurrección del 2 de mayo de 1808 "se debe a la opinión conocida con el nombre de Espíritu público, opinión que ha formado una segunda naturaleza" la cual "durará mientras haya Españoles" (Canga Argüelles, 1813, p. 15). En su Diccionario de Hacienda define la opinión pública como "tribunal de un carácter singular, erigido por el espíritu 
social" capaz de ejercer "una grande influencia sobre todas las partes del gobierno" en cuanto instrumento de que disponen los ciudadanos (Canga Argüelles, 1833-1834g, I, pp. 372-373). Sostiene también que la opinión pública favorece la superación de los gobiernos absolutos pues favorece la libertad, "baluarte inexpugnable contra el despotismo" (Canga Argüelles 1825,46).

García Monerris sostiene que Canga Argüelles vio la economía política como una ciencia nueva capaz de favorecer la creación de riqueza gracias a una "metodología global y retrospectiva" para lograr que la hacienda pública fuera "la inexcusable conexión entre la sociedad y el poder político" (García Monerris 1997,208).

\section{Entre la praxis y la teoría de la hacienda pública}

Entre los años terminales del siglo XVIII y los dos primeros decenios del siglo XIX Canga desarrolló progresivamente sus ideas sobre la crisis de la hacienda absolutista y la hacienda pública liberal. Argumenta que las reformas ilustradas lo ayudaron a entender la naturaleza plural del sistema de impuestos y tasas de España (Astigarraga, 2015, pp. 169-191). Es probable que sus ideas sobre la hacienda pública sean influenciadas por Vicente Alcalá Galiano quien era director general de rentas al ingresar en el ministerio de hacienda en 1798 (Valles Garrido, 1992 y 2008).

Las principales obras de Alcalá Galiano se publicaron en 1783 y 1793 por la Real Sociedad Económica de Amigos del País de Segovia. De los estudios publicados, dos tienen que ver con la hacienda pública y en especial el de 1788, dedicado a los tributos. En este último sostiene, siguiendo Adam Smith, que la riqueza de una nación depende "del trabajo anual de sus individuos", que gracias al trabajo se conforma "el capital del estado" y "mientras mayor sea el capital que emplee anualmente una Nación, será más rica y floreciente" (Alcalá Galiano, 1788, pp. 276 y 278-279).

De sus ideas retomadas por Canga están las de no imponer impuestos sobre los géneros de primera necesidad y sobre los productos que perjudiquen "la libertad del comercio interior" y que las contribuciones deben afectar "las rentas de los propietarios", las cuales son "las más justas y equitativas" porque aseguran la "conservación y propiedad a sus dueños" (Alcalá Galiano, 1788, pp. 295 y 298; Canga Argüelles, 1833-1834e, II, pp. 321-329).

El buen conocimiento de la hacienda absolutista de Canga encuentra su primera formulación crítica en 1800 cuando el ministro de hacienda Cayetano Soler le encomienda preparar una memoria sobre una nueva organización de la Secretaría de Hacienda. Luego de su nombramiento de oficial de la Caja de Amortización de Vales Reales, entrega una memoria en la cual sostiene que el ministerio de hacienda debe superar su objetivo de elaborar "el arte de aumentar los ingresos del erario". Insiste en cambio que su papel es fomentar "la agricultura, la industria y el comercio" que son los "fecundos manantiales" para "mantener la seguridad y bienestar de los pueblos" (Canga Argüelles, 1800, 1833-1834, II, pp. 552-554).

En su memoria sobre la reorganización del ministerio de hacienda argumenta que debe "conocer bien el Estado, su poder, o debilidad, sus riquezas, o su pobreza", procurar a los habitantes "los medios de enriquecerse" para ofrecer "una corta porción de sus bienes a las necesidades del gobierno" y, finalmente, buscar el medio "más cómodo y menos gravoso" de "exigir los impuestos" y dar "una exacta cuenta y razón del gasto general del Estado". La implementación de estos objetivos requiere conocer la población y un buen conocimiento de las provincias, fomentar la agricultura, las manufacturas, el comercio y el sistema de rentas "de cuyas operaciones depende la pobreza o la riqueza" de la nación (ibíd.).

También Canga propone renovar el ministerio de hacienda con una nueva organización en tres secciones: la primera, encargada del "conocimiento exacto de la población y riqueza de cada provincia y del reino" en general; la segunda, encargada de "la parte legislativa y protectora de la agricultura, las artes y el comercio"; y, la tercera encargada "de los ingresos, las salidas, cuenta y razón de las rentas y deuda de la corona" (ibíd.). Vale la pena subrayar que Canga, gracias a su capacidad de comprender la unidad existente entre gastos, ingresos y deuda pública, ascendió a responsable de la sección de la balanza de comercio del ministerio de hacienda.

Dos años más tarde y apenas a cuatro años de su primer nombramiento en el Ministerio, presenta una nueva memoria sobre nivelar los ingresos y los gastos del erario en tiempos de paz. En ella acentúa sus críticas a la hacienda de antiguo régimen argumentando que "un sistema 
sabio no se apropia de los ingresos del contribuyente", realiza "los gastos a la verdadera conveniencia pública" y arregla "el cargo y la data bajo un pie de economía", es decir, del ahorro. Sostiene también que los gastos públicos deben lograr que "quede lo suficiente para pagar las deudas anteriores". El sistema de hacienda "en la época actual deberá fomentar la riqueza nacional" y cimentar "el crédito público" (Canga Argüelles, 1802, 1833-1834, II, pp. 635-650).

Luego de un examen detallado de los ingresos públicos propone las "reformas que parecen necesarias". Si bien exceptúa reformar los gastos de la casa real, recordando pero que ellos aumentaron desde 35,6 a 91 millones de reales entre 1737 y 1788, aconseja reducir los gastos de la Secretaria del Despacho de Estado, del Consejo de Hacienda y de la Tesorería General en modo tal que los gastos totales sean de 644 millones de reales con un déficit de 3.1 millones de reales. Termina por preguntarse "¿Cómo pagar los 700 millones de atrasos?, ¿De dónde ha de salir lo necesario para los gastos imprevistos?". La única respuesta que formula es que "en semejante situación, la prudencia, la conveniencia y la razón dictan que se les franqueen auxilios en vez de establecer exacciones" (ibíd.).

Gracias a sus conocimientos de la Real Hacienda, a su experiencia en la gestión del Real Patrimonio Valenciano y a su estudio de la historia, Canga reflexiona en 1808 sobre la necesidad "de reconstrucción de un nuevo pacto entre la monarquía y los vasallos que operara de manera directa y sin mediaciones" de cuerpos intermedios (García Monerris, 2005, p. 247).

Muchos años antes del Congreso de Cádiz, Canga se dio cuenta que la hacienda pública era irracional e incoherente y que debía por lo tanto ser refundada para "proporcionar los ingresos a la fuerza del contribuyente, y los gastos a la conveniencia pública" con el fin que "quede suficiente para pagar las deudas anteriores" y "fomentar la riqueza nacional, cimentando el crédito público" (Canga Argüelles, 1802, 1833-1834, II, p. 636)

Es bastante conocido el papel desempeñado por la economía política en las Cortes de Cádiz para dar vida a una nueva economía pública liberal gracias a la participación de numerosos diputados (López Granado, 2012, 233256; López Castellano, 1999; Usoz 2015, pp. 105-127). Es en esta trágica ocasión para la hacienda pública que el ministro de hacienda Canga sostiene que "si no adoptamos las ideas liberales" no se logrará discutir si "la nación está obligada a satisfacer los gastos antiguos de su gobierno". Recuerda además que es necesario tener presente que "la teoría del crédito tiene una íntima conexión con la moral pues "los principios de ésta y de aquél son unos mismos". Si "la moral de los gobiernos no puede ser distinta de la de los individuos" es necesario que "la nación reconozca la deuda antigua", la de la monarquía, junto con "la moderna", la del nuevo orden constitucional, "y asegure de algún modo su pago" (Canga Argüelles, 1811b, pp. 782-783).

Según Canga la deuda antigua reconocida en julio de 1808 es de 5.9 billones de reales vellón, que es la deuda antigua, a la cual se agrega la deuda nueva de 3.5 billones de reales vellón derivada de la guerra contra Francia. La deuda total comporta un pago anual de intereses por 139,1 millones de reales vellón (Canga Argüelles, 1811b, pp. 782-783). Concluye su estimación de la deuda nacional diciendo que "sin tener en cuenta la progresión de las riquezas del estado por la mayor o menor circulación" no es posible hacer un cálculo de los impuestos necesarios sin tener presente el incremento o la disminución de la riqueza. Critica así el método antiguo de calcular los impuestos repitiendo el monto del año precedente sin tomar en cuenta el incremento los gastos, con el resultado que aumenta el déficit y por lo tanto la deuda pública. En su calidad de ministro de hacienda presenta una cuenta pública que ilustra "la extensión de las obligaciones del tesoro y el valor de las rentas" recaudadas para que el Congreso "fije a cada clase [social] su cuota" de tributos y así "se acabará hasta con las sombras del despotismo" (Canga Argüelles, 1811b, 794-795)

Su doctrina del crédito público parte del principio que si un particular o un gobierno "pide dinero a préstamo" debe seguir siempre "las condiciones del contrato", que son respetar el pago de los intereses y de amortización del préstamo. Sostiene que esta idea del crédito público deriva "de lo que la historia enseña" y "de lo que los economistas aconsejan" y el gran principio se reduce a saber "que sin confianza no hay crédito, que no hay confianza sin seguridad en el acreedor" que cumplirá sus promesas. La seguridad, precisa, se obtiene saldando los intereses y la amortización del préstamo "con caudales" y estableciendo la "plaza para el pago", evitando cualquiera coacción sobre los acreedores (Canga Argüelles, 1811b, p. 789). 
Del principio y de las condiciones del contrato nacen los mecanismos que generan la confianza y la seguridad del crédito público. El primero "elimina el misterio de la deuda pública dando publicidad a "los caudales que entran y salen del tesoro" y con la debida publicidad a la inversión de los fondos obtenidos del préstamo. El segundo mecanismo es el reconocimiento de todas las deudas contraídas por "las generaciones presentes, pasadas y los que nos suceden". El tercer mecanismo es que las Cortes y el gobierno declaren que los contratos celebrados entre los ciudadanos y el gobierno tienen las mismas condiciones que las celebradas entre los particulares y se garantice a los acreedores que los gobiernos no introducirán rebajas a las sumas prestadas. El cuarto mecanismo es impedir la anulación de los intereses y del capital de los vales reales, el papel moneda. Finalmente, el quinto y último mecanismo tiene que ver con la libertad de cambio del dinero por "un valor mayor o menor que el que le diere el comercio", es decir el que establece el mercado, y en esta forma se concilia el respeto "de la propiedad con los principios de la buena fe" (Canga Argüelles, 1811b, pp. 789-793).

La Memoria de hacienda que Canga presenta al Congreso contiene también las normas que permiten extinguir la deuda pública. Sostiene que el monto total de la deuda pública no debe exceder "a un sexto al de la riqueza territorial e industrial del país". El Congreso debe decretar que nación está obligada a pagar todas las deudas antiguas y modernas, así como todas las contraídas para la defensa del país durante la invasión francesa. En seguida, se reconocerá inmediatamente las deudas y se suspenderá el pago de las deudas a las potencias enemigas. Establece luego el orden según el cual se liquidarán las deudas, precisando explícitamente las instancias administrativas encargadas, que las pagarán en billetes de 1500 reales los cuales serán admitidos según su valor comercial para el pago de contribuciones y en la compra de bienes públicos (ibíd.).

La reducción de la deuda pública obliga al gobierno vender en subasta pública todas las propiedades rurales y urbanas de las órdenes militares, los baldíos no necesarios de los pueblos, las fincas pertenecientes a conventos destruidos por la guerra, las fincas reales, la séptima parte de los bienes de la Iglesia, las propiedades que fueron de Manuel Godoy, la mitad de los bienes de las obras pías y las pertenecientes a los rebeldes. La subasta pública de los bienes podía rendir 7,1 billones de reales (ibíd.).

Gracias a su exposición Canga logra en marzo de 1811 el examen y aprobación del primer presupuesto nacional y en junio del mismo año se inicia la reorganización de la estructura administrativa del ministerio de hacienda y la racionalización de la gestión tributaria (López Castellano, 2005, pp. 145-175; 2009, pp. 216-238)

El nuevo crédito público es la primera parte y la más urgente de la labor ministerial de Canga. La otra es la relativa a la necesidad de superar el sistema de las rentas provinciales dando vida a una nueva contribución territorial fundada "en la riqueza del pueblo". La nueva contribución territorial parte de la idea que "la utilidad del erario no está en la numerosa multitud de tributos, sino en que éstos sean de tal calidad que se concilien con haberes y fuerzas del que los haya de pagar". Estos tributos "deben fomentar la riqueza pública" y conciliar, citando a Gándara, "el interés del soberano y del vasallo". La nueva contribución territorial debe "recaer sobre los fondos que proporcionen las riquezas", ser proporcional a los ingresos de los ciudadanos, no debe perjudicar "las fuentes de la riqueza" y deben recaer sobre todos los ciudadanos sin afectar los consumos de primera necesidad que perjudican a los pobres. Finalmente es necesario garantizar la publicidad de los ingresos de la contribución territorial y los gastos de recaudación deben ser lo más reducidos posibles (Canga Argüelles, 1811c, pp. 99-100 y pp. 111-112).

En 1813 reflexiona su labor de ministro de hacienda y sostiene que su plan de construcción de la hacienda pública constitucional encuentra su origen en "la opinión conocida generalmente con el nombre de espíritu público" que nace con el levantamiento de Madrid del 2 de mayo de 1808 (Canga Argüelles 1813, 63). Conviene detenerse sobre sus Apuntes para comprender las nuevas ideas liberales de la hacienda pública que se conforman en las Cortes.

Dos son las principales novedades visibles en los objetivos de la nueva hacienda pública y en la implementación de ellos a nivel institucional. El objetivo inmediato es "reanimar el crédito público" para hacer frente a los gastos de la lucha contra el invasor y para poder sostener el costo de los cuerpos administrativos del nuevo Estado constitucional. Reanimar el crédito público significa detener la emisión de la deuda pública flotante representada por los vales reales y 
dar vida a una deuda pública consolidada con base al reconocimiento de todas las deudas presentes y pasadas con el fin de generar confianza a nivel de los acreedores. Para lograrlo hay dar reconocer que la deuda flotante y los vales reales deben tener "el valor que le diere el comercio", admitiéndolos en el "pago de contribuciones" (Canga Argüelles, 1813, pp. 12-14).

Una vez activada esta primera medida, se debe pasar a reformar completamente a la hacienda pública dando la debida publicidad de todos sus actos. Se podrá así pasar a la medida siguiente que es "arreglar la dirección y manejo de los ramos de hacienda" a través de la reducción del número de Direcciones y de oficinas superiores, mejorar la justicia fiscal y crear la Sala de Gobierno de Hacienda. Calcula Canga que la reforma de los ramos de hacienda permitió un ahorro anual de 1,2 millones de reales de vellón (Canga Argüelles, 1813, pp. 20-21).

Los resultados de su acción ministerial son visibles en la mayor capacidad coactiva del Tribunal Mayor de Hacienda y sobre todo en el nuevo sistema de cuentas "que asegure la recta inversión de los sacrificios del pueblo" Canga Argüelles 1813, p. 40). El nuevo orden administrativo y contable permite "reformar los gastos del estado" privilegiando, dada la situación bélica, los gastos militares y reformando el cuerpo de funcionarios y reduciendo de "un tercio los pensionistas" (Canga Argüelles, 1813, pp. 20-21).

Las reformas del gasto y de los ingresos públicos se hicieron a partir de su idea que era necesario incentivar la riqueza nacional para lo cual los impuestos debían recaer sobre los fondos que generan la riqueza, en especial sobre las propiedades, y debían ser proporcionales al ingreso de los ciudadanos. Con esta finalidad se eliminan los arbitrios directos, los diezmos y los derechos feudales, y se eliminan los mayorazgos permitiendo a todos los hijos acceder a la herencia de sus padres. Se refuerzan los derechos de propiedad concediendo permiso "a los pueblos para arbitrar los pastos comunes, y acordar cerramientos de heredades públicas y particulares" (Canga Argüelles, 1813, p. 40).

La venta de los bienes de la corona, de baldíos, de bienes de monasterios destruidos, de fincas comunes y de propiedades confiscadas permitió reabsorber una parte importante de la deuda flotante e incrementar los ingresos públicos. Este resultado se logra admitiendo el pago de las contribuciones en vales reales a precio de mercado y autorizando el pago de hasta una tercera parte de los créditos por el aprovisionamiento a los ejércitos. Se permite a la hacienda pública pagar la deuda pública con billetes de crédito para adquirir los bienes públicos en las subastas y para indemnizar a los "dueños de señoríos y jurisdicciones. Se autorizó también que los detentores de vales reales pudieran adquirir bienes pertenecientes a la corona (Canga Argüelles, 1813, pp. 16-17).

$\mathrm{Al}$ ser nuevamente nombrado ministro de hacienda y de ultramar en 1820 presenta a las Cortes una nueva memoria sobre el crédito público. En ella vuelve a insistir sobre "el descrédito del tesoro público", un mal arraigado por el "habitual olvido de las promesas más solemnes" del gobierno. Con un menor entusiasmo que en 1811 vuelve a recordar que la experiencia y la teoría “enseña los medios para remediar" los errores del pasado (Canga Argüelles, 1820, p. 42).

Su primera acción fue dar vida a la Junta de Crédito Público que proporcionó la información relativa a deuda nacional en 1818. La suma de la deuda que paga intereses es de 6,8 billones, que, sumada con la flotante, que no paga intereses, de 7,4 billones, asciende a 14,2 billones de reales vellón, es decir, casi el doble de la deuda de 1811, estimada entonces en 7,8 billones de reales vellón. En otras palabras, la tasa de crecimiento de la deuda pública fue del 7,8\% anual entre 1811 y 1818 (Canga Argüelles, 1820, pp. 47-52).

El rápido crecimiento de la deuda pública lo ayuda a expandir su precedente análisis de 1811. Argumenta que la reducción de los ingresos públicos desciende de la intolerancia de las obligaciones impuestas a los contribuyentes. El contribuyente responde escondiendo "una parte del rendimiento de su trabajo", con el resultado que los ingresos del estado serán inferiores a los gastos públicos (Canga Argüelles, 1820, p. 26).

Replantea la necesidad de establecer la confianza impositiva lo cual requiere una "conducta franca" del gobierno "que manifieste al pueblo los ingresos y las salidas de los fondos del erario" con el fin que todos se convenzan "de la integridad con que se manejan los fondos públicos" (Canga Argüelles, 1820, pp. 27-28). Conviene por lo tanto dar publicidad a las cuentas del estado, es decir, nutrir a la opinión pública de la información evitando "la conducta observada 
en orden a las deudas contraídas por el gobierno" de esconderlas y desconocerlas, como se ha hecho desde el siglo XVI (Canga Argüelles, 1820, pp. 19-20).

Una vez restablecida la confianza pública, la publicidad de las cuentas del estado incrementará la confianza hacia el crédito público confirmando, cuanto ya había dicho en 1811 que los contratos públicos, al igual que las obligaciones entre privados, deben ser siempre respetados. Sin este reconocimiento "las obligaciones extraordinarias del tesoro público" serán imposibles "sin los auxilios fecundos del crédito" permitiendo establecer "la unión benéfica de los intereses individuales y los del erario" (Canga Argüelles, 1820, p. 4).

La relación de confianza del crédito público podrá "en circulación la riqueza pública haciendo refluir en el erario" una cuota de ella. En esta forma se fomentará "los lazos de la unión entre los gobernantes y los gobernados" y se facilitará "los recursos inmensos de que carece el gobierno". Sostiene que hay que tener presente que "una vez perdido el crédito es difícil restablecerlo" mientras "una vez cimentado, facilita recurso más pingues que los que proporcionan las minas más abundantes" (ibíd.). Es así como los principios liberales de Canga vuelven a presentar la nueva relación contractual que se establecerá entre los acreedores y el gobierno, relación que hará duradero el nuevo crédito público.

Diez años después de su primera exposición como ministro de hacienda refuerza en 1820 sus ideas que el crédito público requiere el "reconocimiento y pago de deudas antiguas" evitando "las providencias exactivas y violentas" presentes en el pasado que impedían "la libre negociación mercantil de los documentos de la deuda pública" (Canga Argüelles, 1820, pp. 12-18).

En suma, la principal contribución de Canga al nacimiento de las finanzas liberales deriva de su capacidad de establecer un diálogo constante entre la economía política, las prácticas de la hacienda pública y la experiencia histórica. El resultado es una concepción de hacienda pública capaz de conjugar los principios constitucionales con la ardua empresa de dar vida a las finanzas públicas liberales capaces de garantizar la seguridad de los derechos de propiedad conjugándola con la capacidad contributiva de los ciudadanos.

\section{La ciencia de hacienda}

El principal mérito de Canga es formular una nueva concepción de la hacienda pública a partir del método inductivo-deductivo de la economía política, conjugándolo con la teoría política y con la historia, y dando la debida importancia a su experiencia en los mecanismos de la hacienda pública adquirida durante el absolutismo y el naciente estado liberal constitucional.

En las dos ediciones de su Diccionario de Hacienda de 1826 y de 1833-1834 cita las Meditaciones de la economía política de Pietro Verri, presente en su biblioteca, traducida al castellano en 1820. En el prólogo de los "Diccionarios" como en su Elementos de la ciencia de hacienda define la economía pública, siguiendo a Verri, como "una parte de la economía civil, que enseña el modo de engrandecer el estado, empleando en utilidad suya las riquezas; y de hacer opulento el erario con el menor sacrificio del contribuyente". Agrega en seguida que la ciencia de hacienda "descubre los obstáculos que se oponen al bienestar de los pueblos" y que "examina la índole de los tributos, y su influjo sobre los mineros de la riqueza pública, y sobre la moral y las virtudes sociales, que son el apoyo de los gobiernos" (Canga Argüelles, 1833-1834, I, III). Con base a estos principios presenta la ciencia de hacienda como "aquella parte de la economía política que da reglas para fijar los gastos públicos de la nación; y para sacar de la riqueza la cantidad necesaria para su pago, asegurando su exacto cobro y aplicación a los objetivos a que se destina" (Canga Argüelles, 1825, p. 11).

Considera las finanzas públicas relacionadas con "la ciencia de gobierno" que toma en cuenta la multiplicidad de intereses presentes en la sociedad "cada uno de los cuales, como los comerciantes, los nobles y los plebeyos miran las operaciones de hacienda de un modo particular a su estado; y a la naturaleza de sus profesiones". A los intereses sociales añade la diversidad de opinión presentes en la sociedad "sobre los puntos principales de la administración" de hacienda (Canga Argüelles, 1825, p. 7).

Si bien la economía pública presenta fuertes nexos con la economía política y la ciencia política, ella no debe confundirse con la ciencia administrativa que es estática, fundada en "cánones invariables", interesada en "mantener el vínculo principal de las relaciones con el estado" para salvaguardar el orden social. A diferencia de la ciencia administrativa, la "ciencia económica y 
la de hacienda es variable" pues la primera "trata del movimiento de la sangre del cuerpo político" mientras la de hacienda "tiene que acomodar sus preceptos a la situación peculiar de las clases que componen el estado" (Canga Argüelles, 1833-1834d, I, p. 575).

La dimensión administrativa de la hacienda se limita al conocimiento de las contribuciones, de los propios, de los arbitrios, de los bienes comunales, de las obras públicas, de la beneficencia pública, de la policía, del fomento de la industria, de la agricultura y del comercio y de los empleados de hacienda (ibíd.). Corresponde por lo tanto a la administración de la hacienda pública acrecentar "el bien público, la común utilidad y la recta administración de justicia" que permiten que la sociedad "disfrute tranquila del reposo, de la seguridad y del producto de la industria" (Canga Argüelles, 1833-1834d, I, p. 573).

El arquitrabe de la innovación aportada por Canga a las finanzas públicas fue apoyarla en la riqueza pública. Sostiene que la riqueza "debe ser la que regule la magnitud de los gastos, y las cualidades de los instrumentos que se adoptaren para hallar los fondos necesarios" para sostener los gastos (Canga Argüelles, 1825, p. 11). Con esta especificación se precisa la segunda novedad del pensamiento de Canga que los gastos públicos son los que definen y regulan los ingresos del gobierno, provenientes de las contribuciones y del crédito público.

En cuanto arquitrabe de las finanzas públicas, la riqueza encuentra su detonador en la búsqueda de la "abundancia de todas las cosas que son capaces de satisfacer nuestros deseos en cantidad superior a ellos mismos" y al convertirse los deseos en necesidades "aumentan con ello las producciones capaces de satisfacerlas" (Canga Argüelles, 1825, pp. 72-73). Esta búsqueda es la que genera nuevas producciones que asocian el trabajo con el capital, generando el valor de las mismas para quien las produce como para el capitalista que "facilita los medios necesarios para lograrlo" (Canga Argüelles, 1825, pp. 73-74).

La definición de riqueza ofrecida por Canga, que conjuga la motivación sensualista con la objetiva del trabajo y el capital, tiene el mérito de superar la idea de riqueza mercantilista entendida como un fondo acumulado en metales preciosos. De allí que se pueda decir que Canga, como todos los economistas clásicos, concibe la riqueza como el flujo de ingresos generados por el trabajo dependiente e independiente, por la propiedad de la tierra y por los capitales. En este flujo dinámico de riqueza se incluye también los ingresos de los comerciantes y de los servicios que son "los que hacen los consumos" (ibíd.). En suma, la riqueza de la nación es la suma de los ingresos del trabajo y de los consumos realizados por los servicios.

A mi entender Canga se inspira en las ideas de Adam Smith, quien habla de la riqueza diferenciando el producto bruto del real. La riqueza bruta es el producto que la actividad humana no logra multiplicar, el producto susceptible de serlo y el producto limitado e incierto. La riqueza real es el producto anual de las tierras y del trabajo y haciendo referencia a la división del producto real distingue la renta de la tierra, los salarios del trabajo y las ganancias del capital (Smith, 1776, I, XIX, pp. 236-237 y 258).

Canga retoma la idea de riqueza real de Smith y denomina renta tanto el producto anual de la tierra como la del trabajo y del capital. De allí que para él la riqueza es la suma de todas las rentas generadas al interior de España. Al hablar de las clases económicas que se reparten el producto real dice que "son el trabajo industrial, los dueños territoriales y los capitalistas". Sostiene que incluye en el reparto del producto de la industria los trabajadores mientras los dueños territoriales dan una porción de su renta a los arrendatarios. Todos los productores dan una parte de su renta a los capitalistas mientras los comerciantes lo obtienen de los consumos. En síntesis, cada clase económica recoge la parte "de producto a cuya formación hubiera concurrido" y por lo tanto la suma de los ingresos de las clases económicas forma "la riqueza general de la nación” (Canga Argüelles, 1825, pp. 72-74 y 1833-1834c, I, p. 361).

De toda la renta generada, Canga descuenta la parte destinada a generar los nuevos productos, que denomina "productos economizados", es decir los que sirven "para emplearlos en la producción de otros". Identifica esta renta neta como "la reproducción de la riqueza" que contribuye a "la formación de la acumulación de los capitales" (Canga Argüelles, 1825, pp. 16-17). La acumulación del capital es "un capital tan íntimamente enlazado con el trabajo, como a su división" y, por lo tanto, es "inútil proteger la industria mientras el capital no pueda fomentarla". La acumulación del capital es entonces "la operación que limita los gastos, con el fin de dedicar a la reproducción de sus riquezas" (Canga Argüelles, 1825, pp. 16 y 20). 
La definición de la riqueza permite a Canga establecer la parte susceptible de ser apropiada por el Estado. Diferencia la riqueza privada de la riqueza pública, representada la primera por todos los ingresos individuales y familiares generados a lo largo de un año, mientras la riqueza pública, la del Estado, "debe ser la que regule los gastos, y las cualidades de los instrumentos que se adoptaren para hallar los fondos necesarios" para el sostén de los gastos públicos (Canga Argüelles, 1825, p. 11).

Sobre la relación entre la riqueza pública y los gastos del gobierno es más explícito en 1833 cuando escribe que "antes de sujetar al súbdito al pago de nuevos tributos y sacrificios, deben examinarse la calidad de los gastos ordinarios, suprimiendo de los mismos los menos útiles a fin de regular el cargo con la data" (Canga Argüelles, 1833-1834, I, pp. 372-3739). Por este motivo define en 1825 la ciencia de hacienda como "economía pública" y precisa que es "la ciencia que descubre las causas y los medios por los cuales la riqueza pública se aumenta y distribuye en las clases de la sociedad" (Canga Argüelles, 1825, p. 125 y 1833-1834c, I, p. 372).

Su idea que la riqueza pública es "la que regule los gastos" da un nuevo significado a la hacienda pública. En el antiguo régimen son los ingresos del estado la dimensión hacendaria más importante porque el estado tiene el poder de coerción sobre todos los ingresos. Separada la hacienda pública de la riqueza privada, la participación de las clases económicas para sostener con impuestos y tasas los gastos del estado se redefinen en función al ingreso individual y familiar. Los gastos del gobierno dependerán entonces de la evolución de la riqueza pública porque "antes de sujetar al súbdito al pago de nuevos tributos y sacrificios, deben examinarse la calidad de los gastos ordinarios, suprimiendo de los mismos los menos útiles a fin de regular el cargo con la data" (Canga Argüelles, 1833-1834c, I, pp. 372-373).

La riqueza nacional privada y pública está condicionada por factores no económicos y, en especial, por el influjo que ejerce "la civilización" es decir "la seguridad, la salud, las luces, el gasto, las costumbres, el culto y la comodidad". El factor de la civilización influye directamente en la "industria" con el resultado que la actividad económica desfallece donde la civilización es desconocida mientras prospera donde ejerce su influjo (Canga Argüelles, 1825, p. 17).

Para Canga el principal agente condicionante del desempeño económico es la seguridad. Sin seguridad "no hay libertad económica. No existe orden social y sin éste la riqueza no prospera" (ibíd.). La seguridad asume en la cultura económica liberal un papel destacado porque es "la libre facultad de disponer de la riqueza que produce el trabajo, y de los bienes, muebles, raíces y semovientes que se adquieren con la industria, o por los medios legales". Es precisamente a partir de la seguridad que Canga elabora el principio de la coacción fiscal liberal que caracteriza como "el origen de las contribuciones, la obligación de pagarlas y la indisputable autoridad de los soberanos para exigirlas" (Canga Argüelles, 1833-1834h, II, p. 440).

Existen además los obstáculos que impiden el progreso de la riqueza y el crecimiento de la renta que "dimanan de la opinión, o de las leyes". Entre los primeros figuran los "abusos de religión", que se traducen en "una moral tan rígida, como equivocada" (Canga Argüelles, 1825, pp. 44-49). Los obstáculos derivados de las leyes son las que enervan la administración de justicia, afectan la seguridad, expanden "los consumos improductivos". Ellos se reflejan en "la falta de buenos y sencillos códigos, y la desorganización de los tribunales" pero también en "las leyes que prohíben los cierros de los terrenos o impiden el rompimiento de los baldíos", en la existencia de gremios, mayorazgos, en el proteccionismo en general y en "los privilegios dispensados a las clases no productivas" (Canga Argüelles, 1825, pp. 49-63). En suma, la expansión de la riqueza pública conoce condicionamientos significativos tanto a nivel económico como a nivel político e institucional.

También el consumo influencia la riqueza porque, si bien destruye los valores producidos, tiene el gran mérito de "animar al hombre industrioso a multiplicar los artículos propios para cubrir los deseos" (Canga Argüelles, 1825, p. 75). Condillac y Destutt de Tracy le permiten diferenciar los consumos productivos de los improductivos. Los primeros son "los que alteran el valor de los objetos" para dar vida a "otros capaces de reemplazar los valores destruidos" mientras los consumos improductivos "destruyen el valor de la riqueza y los objetos que las constituyen" (ibíd.).

A diferencia de los consumos privados, "los que los individuos hacen", los públicos, "realizados por el gobierno con la creación de cosas útiles" y "empleando riquezas duraderas" permi- 
ten disminuir "el gasto sucesivo" para asegurar "un bienestar permanente". De allí que los consumos públicos son útiles pues tienen "las ventajas, que la sociedad saca de los objetos que los producen" (ibíd.).

También los consumos públicos "se dividen en productivos y estériles". Los productivos son los "que hace el gobierno para fomentar la industria", como son la construcción de caminos, canales, establecimientos de enseñanza e incluso "los premios concedidos a los sabios". Los consumos públicos no son ilimitados y deben representar entre un cuarto y un sexto de los consumos totales para poder ejercer "una inmensa influencia en el bienestar de la nación". Así todos los consumos productivos entran en "los productos de la industria" y por este motivo "la ciencia de hacienda, al dar reglas que deben seguirse para fijar los gastos públicos de las naciones, deben tener muy en cuenta el manantial y los agentes que producen los objetos capaces de llenarlos" (Canga Argüelles, 1825, pp. 76-77).

Los gastos públicos no deben impedir la producción, la circulación de los productos y no deben afectar el desarrollo general del consumo pues en caso contrario afectan el interés y la utilidad de las actividades individuales y perturban la reproducción del capital. Esto significa "que los gastos públicos de las naciones se satisfacen con la parte que el gobierno toma de la riqueza pública" por impuestos y tasas que se aplican "al sostén de los establecimientos necesarios a la sociedad". La apropiación gubernamental de los ingresos privados se hace comparando "la suma de los gastos" públicos con "la magnitud del sacrificio" privado, es decir el gobierno debe tomar en cuenta el trabajo y la reproducción de la riqueza. El gobierno, como sostiene Montesquieu, fija los gastos públicos tomando en cuenta "la verdadera situación del pueblo, su miseria, o su riqueza" (Canga Argüelles, 1825, pp. 77-79).

Canga estima que en el periodo 1797-1810 el producto bruto de España fue de 10.920 millones de reales y los gastos públicos fueron de 3.061 millones de reales, es decir la mitad de la suma de los consumos totales y el $28 \%$ del producto bruto nacional. Sostiene que se trata de un gasto público excesivo porque no debería haber superado 1.625 millones de reales, el 14,8\% del producto bruto nacional (Canga Argüelles, 1825, pp. 83-84). Comparando los gastos públicos per cápita anota que los de España fueron de 41 reales, similar al de Prusia (45 reales) pero inferior al de Gran Bretaña (166 reales), Francia (98 reales) y Holanda (96 reales) (Canga Argüelles $1825,83-84$ y 122$)$.

La razón por la cual Canga establece que el gasto público no debe "exceder la cuarta parte del consumo total" es que, en "un sistema justo de libertad", los impuestos no deben destruir "las fuentes de su riqueza, ni multar los productos del trabajo" (Canga Argüelles, 1825, pp. 115116). Subraya así que los ingresos públicos nunca deben comportar "un sacrificio de la riqueza privada adquirida a costa del trabajo, de los capitales, y de la industria". Por este motivo los impuestos no deben "recaer sobre los capitales sino sobre los productos" con el fin de evitar la destrucción de la "reproducción de la riqueza".

Hablando en los impuestos, Canga escribe que hay que tener presente "que la opinión influye poderosamente en el sistema tributario; porque ataca la parte nerviosa e irritable del cuerpo político" y subraya la necesidad de eliminarse los tributos "que mereciesen el odio y repugnancia del pueblo" (Canga Argüelles, 1825, pp. 118-120).

Para conciliar los ingresos del estado con el interés social y la opinión pública recomienda un sistema de impuestos "más sencillo, más expedito, y menos costoso" para que los impuestos recaigan siempre "sobre todos los individuos con igualdad" eliminando, por lo tanto, los privilegios que "son atentatorios de los derechos del hombre". Siguiendo estas normas se obtiene un beneficio para el erario público para lograr que "que entre la suma total que paga el pueblo y la que recibe el gobierno haya la menor disminución posible" (Canga Argüelles, 1825, pp. 121).

De la reseña detallada de los diferentes impuestos y tasas, Canga insiste que debe preferirse la tributación sobre el consumo privado "porque repartido sobre el precio de los objetos se les hace insensible" al contribuyente y, al mismo tiempo, se debe evitar de gravar demasiado los bienes necesarios para la subsistencia porque atacan la industria y en especial a los trabajadores (Canga Arguielles, 1825, pp. 123-124).

En su análisis de los impuestos sobre la circulación, Canga sostiene que "cuanto mayor fuere la libertad de comercio, menor el número de las prohibitivas" y redundará en que "será mayor 
los productos de las aduanas" y "más rápida la circulación de los cambios" evitando pesar sobre "la reproducción de las riquezas" (Canga Argüelles 1825, 127-128).

Desaprueba Canga la tasa de patentes que pagan los artesanos y cualquier otro gravamen que impida "emplear el trabajo en los ramos productivos" porque pesan sobre "las clases útiles". Es también contrario a los diezmos, derechos feudales y la tasación sobre el alquiler de las casas que considera contribuciones que "han merecido el nombre de bárbaras". Considera también inconvenientes los impuestos sobre los productos de lujo, las diversiones y las opiniones políticas (Canga Argüelles, 1825, pp. 128-131 y 136-139).

En suma, los impuestos útiles son los que afectan los consumos, la propiedad territorial, la producción agrícola y ganadera, la propiedad inmobiliaria y los del comercio exterior. Deja también vigentes las tasas sobre las transacciones civiles, diplomas, contratos y papel sellado. Insiste en que el nuevo sistema impositivo debe siempre tener presente la opinión pública, el estado de la riqueza y las costumbres, con el fin de preparar los "ánimos para la reforma" y evitar destruir los impuestos antiguos sin motivarlos (Canga Argüelles, 1825, pp. 135 y 139-40).

Con los nuevos impuestos que propone Canga se logra superar "el actual sistema tributario" que "lejos de derramar el peso de los consumos públicos sobre la riqueza de los ciudadanos, en razón de las ventajas que saca de la sociedad, grava más a el pobre que al rico" con el resultado que detiene "la multiplicación de las riquezas, enerva la acción del trabajo, paraliza la industria, ataca los capitales y exime de los impuestos a la clase opulenta" (Canga Argüelles, 1825, p. 142).

La reforma de los gastos y los ingresos públicos garantizan la deuda nacional que hasta ayer se había "segregado de la hacienda". Para unificar la deuda pública en el presupuesto nacional "la pericia de los hacendistas estimulada con la espuela de las necesidades" y la experiencia histórica recomiendan una "reforma de los gastos públicos" que aumente "el número y cuota de los tributos ordinarios" y la aplicación de ambos "recursos al crédito, garantizados por la enajenación de las propiedades de la corona, de las eclesiásticas, de los pueblos y de las tierras baldías. Así el crédito público podrá "facilitar caudales a los gobiernos", sin necesidad de activar contribuciones para favorecer la "utilidad general", las obras públicas, con "sumas que no serían capaces de facilitar los tributos" y que aumentarían incluso "la masa del dinero circulante" (Canga Argüelles, 1825, pp. 149-153,155 y 162-163).

Al considerar siempre insuficiente el ingreso público para favorecer el bienestar de la población, Canga introduce el papel positivo que puede ejercer el crédito público. Lo adquiere cuando "el acreedor", los capitalistas nacionales y extranjeros, se convencen "de la probidad del deudor y de la religiosidad en el cumplimiento de sus contratos" por parte del gobierno. Es con estos pocos principios que se forma "la teoría del crédito de los gobiernos" (Canga Argüelles, 1825, p. 164).

El modelo del crédito público al cual se inspira Canga es el de Gran Bretaña donde, cuando "el gobierno negocia un préstamo, todos están seguros de la puntual ejecución de sus condiciones". Los prestamistas forman "sus cálculos sobre la riqueza pública, y como los tenedores de fondos conocen las ventajas que les resulten de fiárselos". De allí que la confianza crece "al compás de la puntualidad que se observa en el cumplimiento de los contratos" que aumenta si se anticipan los pagos de los intereses y de la amortización de los préstamos mientras "desaparece cuando se suspenden éstos, o se alteran los términos de los contratos". Mientras más se consolida la opinión favorable de los tenedores de bonos más aumenta "la facilidad de adquirir títulos" por el gobierno (Canga Argüelles, 1825, p. 144).

Subraya que un buen ejemplo lo dieron las Cortes de Cádiz cuando reconocieron "todas las deudas de la nación sin diferencia de épocas, ni procedencia". El crédito público "desfallece con las medidas de coacción, empleadas con los acreedores" al rebajar los gobiernos los capitales de las deudas o de los réditos, "alterando la letra de los contratos". También se destruye el crédito público al ocultar "al pueblo el conocimiento de la legítima entrada y salida de los fondos públicos" (Canga Argüelles, 1825, pp.165-175).

La historia de la deuda pública de España permite a Canga sintetizar su idea que el crédito público requiere, "bien concentradas economías en los gastos públicos" y mucho "detenimiento en establecer nuevos impuestos y variar los antiguos". Sin esta reorientación de los gastos e ingresos públicos "ninguna nación puede gobernarse" (ibíd.). 
El crédito público se estimula con la creación y consolidación de la relación de confianza entre los acreedores y el gobierno para instaurar la "buena fe y religioso cumplimiento de los contratos" evitando "toda medida coactiva con los acreedores, asegurar el puntual "pago del capital y réditos de la deuda" y dejar "libre el giro mercantil de los documentos de la deuda" que, como todos los documentos comerciales, están sujetos a "las oscilaciones que las mercancías experimentan en los mercados" (Canga Argüelles, 1825, pp. 176-177).

El crédito público obliga a los gobiernos a elaborar con detenimiento "el Presupuesto de los acreedores legítimos a los sacrificios pecuniarios del pueblo, en debida remuneración de sus servicios, acompañado de la lista siempre terrible de las contribuciones que deban exigirse, para adquirir las sumas suficientes con que realizarlo". El crédito público se convierta en el mecanismo fundamental de la hacienda pública que se refleja en el presupuesto público "cálculo anticipado que se hace del importe de las obligaciones que debe satisfacer el tesoro público y el valor que hayan de rendir las contribuciones ordinarias" que permite calcular "el déficit que resulte para buscar [...] los recursos extraordinarios capaces de igualar la data con el cargo" (Canga Argüelles, 1840, p. 888)

\section{Conclusión}

La economía pública teorizada por Canga Argüelles requiere comprender su trayectoria intelectual y su acción pública. Nuestro autor pertenece a la última generación ilustrada, y como todos los economistas clásicos, atribuye un gran significado a la moral pública. Es este interés el que le permitió dar un peso importante a la opinión pública en los asuntos relativos a la hacienda pública.

Al discutir de economía Canga, como otros de su generación, concede un valor esencial a la "ciencia de gobierno", es decir, a la teoría política que permite entender que todo gobierno exige normas y procedimientos conocidos que nacen de una constitución escrita que establezca la separación de los poderes y garantice la libertad, la seguridad y los derechos del hombre y del ciudadano.

Canga comprende que el objetivo principal de la economía política, la riqueza de las naciones, le permite replantear la hacienda pública para dar vida a la economía pública. Así define la riqueza pública como la parte de la riqueza nacional susceptible de ser apropiada por el Estado para dotar a la sociedad de los bienes públicos que promuevan el crecimiento económico y el bienestar social.

Su idea de la riqueza pública le permitió negar que los ingresos del estado definieran el gasto público, como aconteció durante el absolutismo monárquico. Comprendió que el gasto público es el mecanismo fundamental de la hacienda pública pues distingue los gastos corrientes y los de inversión pública y precisa el financiamiento del crédito del gobierno que se inscribe en la cuenta pública.

La redefinición de la economía pública a partir del gasto le permitió formular su reestructuración a través de la diferenciación entre los consumos privados y públicos y distinguiendo los públicos en productivos e improductivos. Los productivos son los que sostienen las nuevas inversiones en bienes públicos para favorecer el bienestar social mientras los improductivos son los gastos públicos que favorecen la ostentación y el prestigio.

Gracias a su conocimiento y experiencia pública, Canga llega a la conclusión que los gastos públicos deban limitarse hasta representar una cuarta parte del producto bruto nacional. Determinó esta limitación porque comprendió que el gasto público es siempre superior a los ingresos pues las inversiones públicas productivas presuponen un desfase temporal importante entre el momento de la inversión y el momento en que genera un mayor ingreso público.

La limitación del gasto público a un cuarto del producto bruto nacional permitió a Canga redefinir los ingresos públicos con la eliminación de todas las contribuciones que obstaculizaban el crecimiento de la riqueza nacional. Logró así en su desempeño de Ministro de Hacienda generar ahorros significativos en el gasto público.

La redefinición del gasto y del ingreso público le permite reformar el sistema de financiamiento que disponía el estado absolutista desde el siglo XVI, a través de la emisión de los vales reales carentes de toda regulación, sin fecha de vencimiento y amortizados arbitrariamente el tesoro real. 
El nuevo crédito público diseñado y puesto en práctica por Canga parte del principio del reconocimiento de todas las deudas del Estado absolutista y del nuevo Estado liberal en construcción. Este reconocimiento se asocia a la idea que se puede reembolsar la deuda gracias a la alienación de buena parte del patrimonio público con la venta de los bienes de la iglesia, de las tierras baldías y comunales y del patrimonio de la casa real.

Con la eliminación de la deuda preexistente, se logra que el monto de la nueva deuda pública se establezca a partir de la riqueza pública lo cual garantiza a los acreedores la ejecución puntual de las condiciones contractuales de los préstamos públicos.

Establece así que toda deuda pública es un contrato vinculante para el Estado que obliga su cumplimiento, evitando toda medida coactiva contra los acreedores. Se asegura también el puntual cumplimiento del pago de los intereses y de la amortización del capital y se deja a los certificados de deuda libres de circular, como los otros documentos comerciales, sujetos a las oscilaciones de su valor en el mercado. Bajo estas condiciones el crédito público se puede convertir en una nueva fuente de recursos que permite equilibrar el gasto y el ingreso público y generar inversiones en nuevos bienes públicos para la sociedad. Se logra también generar entre los tenedores de bonos la confianza necesaria en la gestión financiera del Estado.

La culminación la nueva hacienda pública es el presupuesto que debe aprobar el Congreso e implementar el gobierno a través del ministerio de hacienda. El presupuesto sintetiza la doble dimensión de la hacienda pública al conjugar las obligaciones que debe satisfacer el tesoro público con las decisiones de la representación política encargada de aprobarlo. En suma, se establece que sin presupuesto no hay organización posible de la nación.

\section{Bibliografía}

Alcalá Galiano, Valentín.1793 [1788]. Sobre la necesidad y justicia de los tributos, fondos de donde deben sacarse y medios de recaudarlos. Segovia, Actas y Memorias de la Sociedad de Amigos del País de la Provincia de Segovia.

Astigarraga, Jesús y Usoz, Javier. 2013. L'économie politique et la sphere publique dans le débat des Lumières. Madrid, Casa de Velázquez.

Astigarraga, Jesús; Guasti, Niccoló y Zabalza, Juan. 2015. The Spanish debate in public finance: a privileged laboratory for enlightened reforms. En Jesús Astigarraga (ed.), The Spanish enlightenment revisited. Oxford, Voltaire Foundation, pp.169-191.

Carmagnani, Marcello. 2014. Economia politica e morale pubblica. Pietro Verri e la cultura economica europea. Bolonia, Il Mulino.

Cabrera, Miguel Ángel y Pro, Juan (eds.). 2014. La creación de las culturas políticas modernas 1808-1833. Madrid, Marcial Pons-Prensas de la Universidad de Zaragoza.

Canga Argüelles, José. 1800, Memoria presentada al rey sobre la organización de la secretaría del despacho de hacienda de España. En Diccionario de Hacienda con aplicación a España, 1833-1834, tomo II. Madrid, Imprenta de Marcelino Carrero y Puerto Carrero.

- 1801. Memoria sobre los obstáculos que encuentra la circulación interna de la moneda en España. En Diccionario de Hacienda con aplicación a España, 1833-1834, tomo I. Madrid, Imprenta de Marcelino Carrero y Puerto Carrero

- 1802. Memoria sobre nivelar en tiempo de paz los ingresos y los gastos del erario español. En Diccionario de Hacienda con aplicación a España. tomo I. Madrid, Imprenta de Marcelino Carrero y Puerto Carrero.

- 1811a. Reflexiones sociales o idea para la constitución española que un patriota ofrece a los representantes de Cortes. Valencia, José Estevan.

- 1811b. Memoria presentada al Consejo Supremo de Regencia sobre las bases del crédito público. En Diario de las sesiones de las Cortes Generales y Extraordinarias, 1810-1813. Madrid. Imprenta de J.A. García, tomo I, 1870.

- 1811c. Memoria sobre las rentas provinciales de Castilla y León. Cádiz, Imprenta Real

- 1813. Apuntes sobre la hacienda pública de España en 1811. Cádiz, Imprenta Tormentaria.

- 1820. Memoria sobre el crédito público que presenta a las Cortes ordinarias de 1820. Madrid, Imprenta García.

— [1825] 1961. Elementos de la ciencia de hacienda. Madrid, Instituto de Estudios Fiscales. 
- 1833-1834a. Dinero o moneda. En Diccionario de Hacienda con aplicación a España, tomo I. Madrid, Imprenta de Marcelino Carrero y Puerto Carrero.

- 1833-1834b. Distribución de la riqueza. En Diccionario de Hacienda con aplicación a España, tomo I. Madrid, Imprenta de Marcelino Carrero y Puerto Carrero.

- 1833-1834c. Economía civil. En Diccionario de Hacienda con aplicación a España, tomo I. Madrid, Imprenta de Marcelino Carrero y Puerto Carrero.

- 1833-1834d. Gobierno de Estado. En Diccionario de Hacienda con aplicación a España, tomo I. Madrid, Imprenta de Marcelino Carrero y Puerto Carrero.

- 1833-1834e. Ministro de hacienda. En Diccionario de Hacienda con aplicación a España, tomo II. Madrid, Imprenta de Marcelino Carrero y Puerto Carrero.

- 1833-1834f. Moral de la hacienda. En Diccionario de Hacienda con aplicación a España, tomo II. Madrid, Imprenta de Marcelino Carrero y Puerto Carrero.

- 1833-1834g. Opinión pública. En Diccionario de Hacienda con aplicación a España, tomo II. Madrid, Imprenta de Marcelino Carrero y Puerto Carrero.

- 1833-1834h. Propiedad. En Diccionario de Hacienda con aplicación a España, tomo II. Madrid, Imprenta de Marcelino Carrero y Puerto Carrero.

- 1833-1834i. Riqueza. En Diccionario de Hacienda con aplicación a España, tomo II. Madrid, Imprenta de Marcelino Carrero y Puerto Carrero.

- 1840. Presupuestos. En Suplemento. Diccionario de Hacienda con aplicación a España. Madrid, Imprenta de Calero.

Comín, Francisco. 2000. Canga Argüelles, un planteamiento realista de la hacienda liberal. En Enrique Fuentes Quintana (ed.), Economía y economistas españoles. Barcelona, Galaxia Gütenberg-Círculo de Lectores, tomo 4, pp. 413-439.

Fernández Santillán, Javier. 2015. From the 'voice of the people' to the freedom of press: the birth of public opinión. En Jesús Astigarraga (ed.), The Spanish enlightenment revisited. Oxford, Voltaire Foundation, pp. 215-233.

Fonseca Cuevas, Palmira.1995. Un hacendista asturiano: José Canga Argüelles. Oviedo, Real Instituto de Estudios Asturianos.

García Monerris, Carmen. 1996. Las Reflexiones Sociales de José Canga Argüelles: del universalismo absolutista al liberalismo radical, Revista de Estudios Políticos (94), pp. 203-228.

- 1997. Entre la economía política y la administración: el ideario del primer Canga Argüelles (1798-1805. En Juan José Gil Cremades (ed.), La configuración política del estado liberal en España. Huesca, Escuela Universitaria de Estudios Empresariales de Huesca, pp. 203-215.

- 2000. Reflexiones Sociales y otros escritos. Madrid, Centro de Estudios Políticos y Constitucionales.

- 2005. La corona contra la historia. José Canga Argüelles y la reforma del Real Patrimonio Valenciano. Valencia, PUV.

López Castellano, Fernando. 1999. El pensamiento hacendístico en las Cortes de Cádiz. Madrid, Instituto de Estudios Fiscales.

López Granado, Fernando. 2012. Las Cortes de Cádiz y la implantación del buen orden económico (1810-1814), Historia Constitucional (13), pp.233-256.

Martínez Cochero, Luis Alfonso. 1977. Un discurso de Canga Argüelles. Boletín de Estudios Asturianos (90-91), pp.10-16.

Normante y Carcavilla, Lorenzo 2000 [1784]. Discurso sobre la utilidad de los conocimientos económicos-políticos. En Proposiciones de Economía Civil y otros escritos. Zaragoza, Instituto Fernando El Católico.

- 2000 [1785]. Proposiciones de educación civil y comercial. En Proposiciones de Economía Civil y otros escritos. Zaragoza, Instituto Fernando El Católico.

Pescosolido, B.A. y Barbara Rubin. (2000).The web of group affiliations revisited: social life, postmodernism and sociology, American Sociological Review (1), pp. 52-76.

Simmel, Georg. 1955 [1908]. The web of group affiliations. En Conflict and the web of group affiliations. New York, s.i.

Smith, Adam. 1976 [1776]. An inquiry into the nature and causes of the wealth of nations. Oxford, Clarendon Press. 
Usoz, Javier. 2015. Political economy and the creation of the public sphere during the Spanish Enlightenment. En Jesús Astigarraga (ed.), The Spanish enlightenment revisited. Oxford, Voltaire Foundation, pp. 105-127.

Vallejo Pousada, Rafael. 2015. Las vicisitudes de la deuda pública en un periodo turbulento: de Canga Argüelles a Mon, 1800-1850. En Carlos Álvarez Nogal y Francisco Comín (eds.), Historia de la deuda pública en España (siglo XVI-XXI). Madrid, Instituto de Estudios Fiscales.

Valles Garrido, José Manuel. 1992. Vicente Alcalá Galiano. Sobre la economía política y los impuestos. Segovia, Academia de Artillería.

- 2008. Ciencia, economía política e ilustración en Vicente Alcalá-Galiano. Centro de Estudios Políticos y Constitucionales, Madrid. 